\title{
Effects of Sex and Gender on Adaptations to Space: Reproductive Health
}

\author{
April E. Ronca, PhD, ${ }^{1,2}$ Ellen S. Baker, MD, MPH, ${ }^{3}$ Tamara G. Bavendam, MD, MS, ${ }^{4}$ Kevin D. Beck, PhD, ${ }^{5}$ \\ Virginia M. Miller, PhD, ${ }^{6}$ Joseph S. Tash, PhD, ${ }^{7}$ and Marjorie Jenkins, MD $^{8}$
}

\begin{abstract}
In this report, sex/gender research relevant to reproduction on Earth, in conjunction with the extant human and animal observations in space, was used to identify knowledge gaps and prioritize recommendations for future sex- and gender-specific surveillance and monitoring of male and female astronauts. With overall increased durations of contemporary space missions, a deeper understanding of sex/gender effects on reproduction-related responses and adaptations to the space environment is warranted to minimize risks and insure healthy aging of the men and women who travel into space.
\end{abstract}

\section{Introduction}

$\mathbf{T}$ O DATE, JUST $15 \%$ of U.S. astronauts have been women, but the numbers are increasing, as evidenced by women achieving for the first time parity with men in the 2013 National Aeronautics and Space Administration (NASA) Astronaut Class. With the transition from the relatively shortduration space shuttle missions to the longer-duration International Space Station (ISS) expeditions, there is a need to review and update biomedical research priorities. Physiological responses of men and women during spaceflight appear to be generally similar; however, there are major gaps in knowledge. Research recommendations set forth in the 2002 report, Sex, Space, and Environmental Adaptation ${ }^{1}$ have not been adequately addressed. Recent biomedical studies on Earth further highlight fundamental differences in the physiology and health of men and women. Close attention to the influence of sex and gender in adaptation to space is warranted, and indeed, overdue.

Through a sex and gender lens, major influences of the space environment (viz., radiation, microgravity, and stress) on reproduction and physiological systems central to reproductive processes (i.e., endocrine and urogenital systems) were considered. This report on reproductive health in relation to space adaptation provides an overarching perspective on current sex and gender evidence, identifies knowledge gaps, establishes a framework for future work, and outlines key recommendations to direct future translational research and infrastructure.

\section{Major Influences of the Space Environment \\ Radiation}

Radiation dose to crew is mission-specific and dependent on multiple factors such as mission destination and duration, vehicle and habitat design, and solar conditions. Typical ISS exposures for a 6-month mission in low-Earth orbit are on the order of 54 to $108 \mathrm{mSv}$ with exposure levels varying with solar activity and ISS altitude (NASA-Johnson Space Center Radiation Health Office, personal communication with Janice Huff, 2013). ${ }^{2}$ Exposures during interplanetary travel required to reach Mars and on the Mars surface are far greater, with annual exposures spanning 210 to $1,070 \mathrm{mSV}$ and 80 to $330 \mathrm{msV}$, respectively. Relative to other organ systems, the gonads are highly sensitive to radiation exposure. ${ }^{3}$ In men and women, temporary infertility is associated with high-dose,

\footnotetext{
${ }^{1}$ Space Biosciences Research Branch, NASA Ames Research Center, Mountainview, California.

${ }^{2}$ Departments of Obstetrics and Gynecology, Neurobiology and Anatomy, and Molecular Medicine and Translational Science, Wake Forest School of Medicine, Winston-Salem, North Carolina.

${ }^{3}$ NASA Medical Officer and Astronaut (Retired), Johnson Space Center, Houston, Texas.

${ }^{4}$ Women's Urologic Health, NIH/NIDDK, Bethesda, Maryland.

${ }^{5}$ Department of Neurology and Neurosciences, Rutgers-New Jersey Medical School, Newark, New Jersey.

${ }^{6}$ Departments of Physiology and Surgery, Mayo Clinic College of Medicine, Rochester, Minnesota.

${ }^{7}$ Departments of Molecular and Integrative Physiology and Urology and the Interdisciplinary Center for Male Contraceptive Research and Drug Development, University of Kansas Medical Center, Kansas City, Kansas.

${ }^{8}$ Department of Internal Medicine, Laura W. Bush Institute for Women's Health, and Rush Endowed Chair for Excellence in Gynecology Oncology, Texas Tech University Health Sciences Center, Amarillo, Texas.
} 
acute radiation exposure-for men, $150 \mathrm{mSv}$ acute $\mathrm{x}$-rays , and for women, 650 to $1500 \mathrm{mSvV}$ acute $\mathrm{x}$-rays or gamma rays to the ovaries. ${ }^{4,5}$ How these tissues respond to exposure scenarios relevant to the space environment with respect to dose, dose-rate, and radiation quality, as well as the combined effects of other spaceflight environmental stressors such as microgravity, has not been addressed. ${ }^{6-8}$

Cancer risk assessment requires evaluation of organ doses (measured in Sv) from dosimetry and physical considerations, which are combined with age- and gender-dependent risk coefficients to project mission risk. Women have a higher incidence of radiation-induced cancers, largely driven by lung, thyroid, breast, and ovarian cancers, and therefore reach maximal safe days in space earlier than men. ${ }^{9}$ There are presently insufficient numbers of humans exposed to spacecharacteristic radiation to accurately assess differential effects on men and women. NASA studies have examined cancer risk in animals following exposure to space radiation (protons and high-linear energy transfer (LET) radiation); however, little attention has been paid to sex differences.

\section{Duration of exposure}

The impact of flight length on reproductive health will require a greater focus with the transition to far longer exposures to both microgravity and space radiation. During the space shuttle era, most exposures were up to $\sim 2$ weeks in duration. In contrast, ISS missions are extending durations of exposure to $6-12$ months. This change is significant with regard to the physiology of sperm production by the testis in the male and the estrous cycle in the ovary in the female. Longer duration missions, spanning multiple reproductive cycles in both men and women, raise a significant knowledge gap concerning the impact of long-term spaceflight on reproductive health.

\section{Microgravity and stress}

There are a number of reproductive health concerns for men and women in space potentially related to microgravity and/or stress (including sleep disruption). Spermatogenesis in men may be impaired beyond effects of radiation exposure. A 120-day Russian bed rest study found that sperm collected after 50-60 days and 100 days exhibited a reduction in live spermatozoa showing active mobility and an increase in the percentage of morphologically/structurally altered spermatozoa. ${ }^{10}$ Basic research studies of male rats exposed to 6 weeks of simulated microgravity have reported severe testicular and epididymal degeneration including massive testicular apoptosis 6 months later. These effects have been postulated to occur due to (a) chronic testicular hyperthermia, (b) invasion of inflammatory cells, and/or (c) catastrophic apoptosis, leading to aspermatogenic dysfunction. ${ }^{11}$ There has been no post-spaceflight research involving humans on this topic.

Reproductive changes during or post flight have not been systematically studied in female astronauts. In female adult mice that were cycling at launch (Space Transportation System [STS]-131, STS-133, and STS-135), spaceflight induced cessation of cycling, loss of corpora lutea, and significantly reduced estrogen receptor mRNA levels in the uterus (HM Holets, University of Kansas Medical Center, unpublished data). ${ }^{12}$ Comparable evaluations in women are lacking.

Systematic data regarding reproductive history in men and women astronauts is lacking. Although many male astronauts have produced children following spaceflight, information on conceptions and birth outcomes upon returning from space are not available. The incidence of infertility following prolonged spaceflights in men and women and the incidence of pregnancy complications in women are not known. In female astronauts who have delayed pregnancy, it will be difficult to parse out the effects of space travel (microgravity, radiation exposure) from natural effects of aging. Female astronauts who experience hypertensive pregnancy disorders may require additional monitoring for cardiovascular disease, because on Earth these disorders are associated with increased risk of future adverse cardiovascular events such as stroke and myocardial infarction. ${ }^{13}$

\section{Physiological Systems Central to Reproductive Function}

\section{Endocrine system}

The hypothalamic-pituitary-gonadal (HPG) and hypothalamicpituitary-adrenal (HPA) axes cross-communicate through neuronal signaling and hormonal negative feedback. Several hypothalamic neurotransmitters are known to be altered by real or simulated microgravity or severe changes in gravity, namely histamine (increases), ${ }^{14}$ serotonin (decreases), ${ }^{15}$ oxytocin (decreases), ${ }^{16}$ norepinephrine (decreases), ${ }^{17}$ and to a lesser magnitude, glutamate (decreases). ${ }^{18}$ These neurochemical disparities may be a direct result of the significant change in the gravitational environment on neuronal signaling or an indirect effect via the hormonal response from the downstream hormonal axes.

Alterations in HPG and HPA axes functioning have been reported following spaceflight. Most evaluations focused on the reduced levels of circulating testosterone in men $^{19}$ that appear to rebound after return to Earth. ${ }^{20}$ This has been recapitulated in short- and long-duration spaceflight and longduration head-down bed rest studies. ${ }^{21} \mathrm{~A}$ recent report ${ }^{22}$ indicated no decrement in serum total, free, and bioavailable testosterone during either long-duration spaceflight or bed rest, but a significant decrease on landing day for the longduration flights and after short-duration spaceflight. The HPA axis, which exhibits both a circadian rhythm and enhanced output of circulating glucocorticoids (i.e., cortisol) in response to stressors, exhibits increased activation during spaceflight, simulated microgravity, and during long-duration stress studies. ${ }^{23-26}$ However, like the gonadal hormones, circulating concentrations of these hormones quickly recover upon return to Earth. ${ }^{27}$

With respect to women, estrogen and gonadal function in space and in simulated microgravity (bed rest) are grossly understudied. Oxytocin, a hormone that acts to attenuate the HPA axis $^{28}$ and dampen stress responses in women, ${ }^{29}$ exhibits longlasting reductions following spaceflight. ${ }^{14}$ Similarly, oral contraceptives (OCs) decrease the release of oxytocin ${ }^{30}$ but do not increase stress responsiveness, as OCs reduce cortisol release in response to stressor exposure as well. ${ }^{31} \mathrm{OC}$ use is not mandatory during spaceflight; however, flight surgeons have recommended 30-35 mcg OCs to female astronauts to provide (a) better suppression of the ovary (less chance for cysts and breakthrough bleeding, depending upon OC formulation) and (b) reduced risk of bone loss. Circulating levels of testosterone, dihydroepiandrosterone, corticosteroid-binding globulin, prolactin, and sex hormone-binding globin are affected by $\mathrm{OCs}^{32,33}$ and are 
involved in stress responses and the regulation of both the HPG and HPA axes. Unfortunately, with ever-changing formulations, periodic reevaluation of oral contraceptive cost-benefit is also required.

\section{Genitourinary system}

While reproductive functions have not been a direct concern during space travel, diseases of organs of the reproductive system have adversely affected flight duration. For example, a serious case of prostatitis in a cosmonaut occurred in 1985 that impacted the length of the mission. ${ }^{34,35}$ Little is known about sexual activity in space, and infrequent ejaculation resulting in accumulation of prostate secretions can support bacterial growth. Hence, the risk of prostatitis may well need to be addressed again during prolonged exploratory travel.

Renal and urinary tract problems are a recurrent issue with space travel. Microgravity and privacy concerns can lead to infrequent and incomplete bladder emptying, increasing the risks for urinary tract infections. ${ }^{33}$ In addition, medications for motion sickness reduce bladder emptying. Formation of stones becomes more likely when hydration is compromised, and microgravity increases the amount of calcium excreted in the urine. Inadequately treated stones and urinary tract infections could eventually impair renal function.

On Earth, urinary tract stones are more common in Caucasian men, but struvite stones are more common in women. ${ }^{36}$ Urinary tract infections are more common in women ${ }^{37}$ and prostatitis occurs only in men. The long-held belief that the urinary tract is sterile is being called into question with emerging work on the urinary microbiome. ${ }^{38}$ There are no data regarding sex differences in spontaneous or unprovoked urinary retention in the age range of the astronauts. However, data regarding provoked urinary retention after surgery, with nearly equal numbers of men and women of similar age to the astronauts, do not show a sex difference. ${ }^{39,40}$

Cumulative experiences in space travel suggest there is no sex difference in the incidence of urinary tract stones during space travel or after returning to Earth, however women have experienced a higher incidence of urinary tract infections in space than men. ${ }^{41}$ Possible explanations for this sex difference include predisposition from women's urethral anatomy, adjustment to voiding in microgravity, a higher incidence of urinary retention, and a higher incidence of catheterization. ${ }^{42,43}$

\section{Interactions of Reproduction with Other Aspects of Health}

\section{Estrogen receptor signaling}

Parallels between spaceflight effects on physiology and aging have been known since the 1960s. ${ }^{44}$ Ground-based studies have identified age-related alterations in estrogen receptor (ER) signaling in many major organ systems. Several of these organ systems have shown changes in experimental animals during spaceflight. Altered ER signaling in these estrogen-regulated systems, shown in Figure 1 are also known to accelerate certain aging processes.

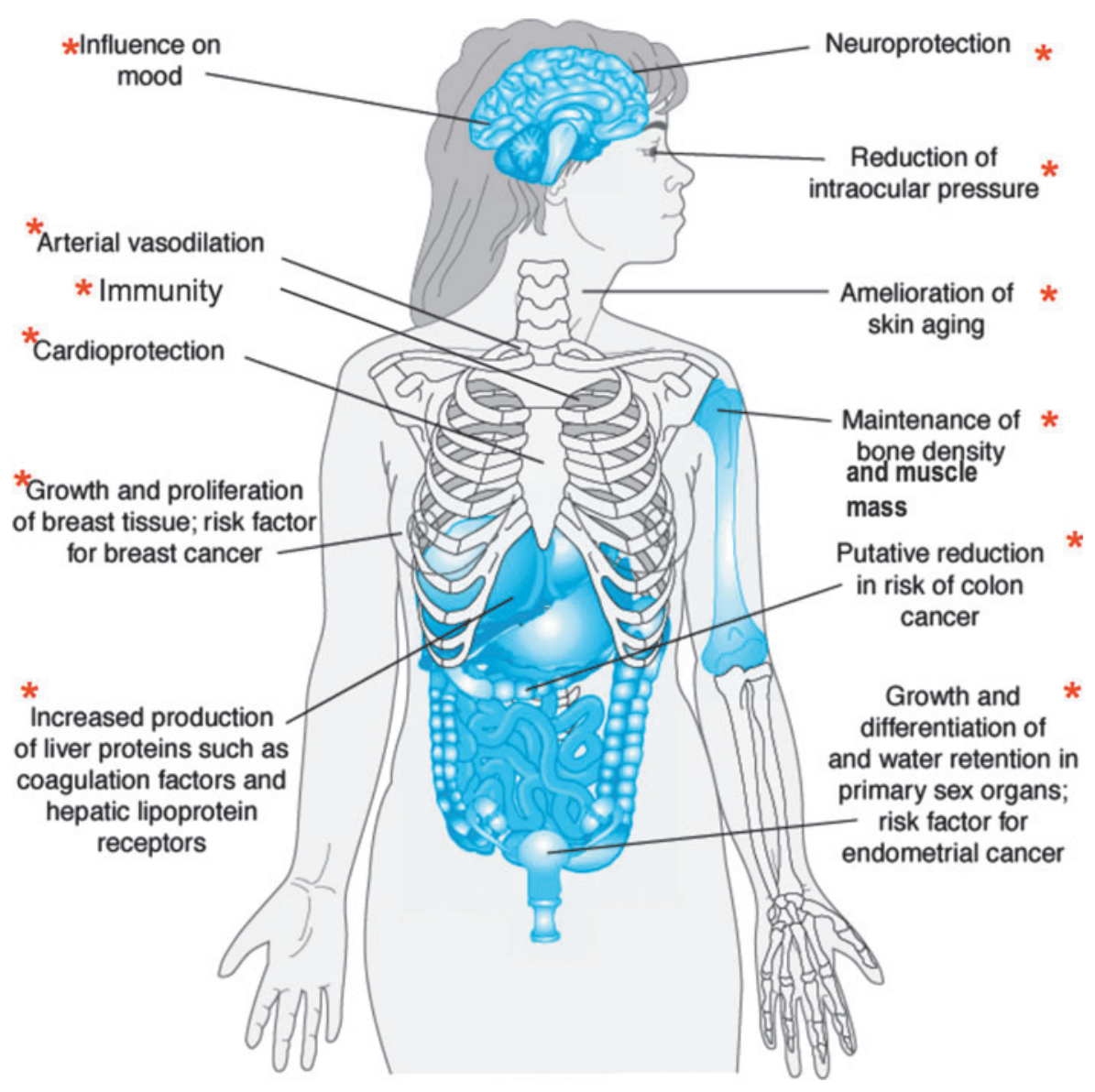

FIG. 1. Estrogen-regulated systems known to be affected by both spaceflight and aging. Adapted from Molina PE. Endocrine Physiology, Third Edition. www.accessmedicine .com. Copyright @ 2010 The McGraw-Hill Companies, Inc. All rights reserved. Color images available online at www.liebertpub .com/jwh 
The spaceflight-induced decline in multiple physiological systems may involve a common mechanism in dysregulation of reproductive steroid receptor-dependent signaling pathways. If this is true, then spaceflight is likely to reduce gonadal function in both men and women. A central crosscutting question for space- and ground-based study is whether there are sex differences in altered estrogen signaling in the spaceflight-affected and aging systems. Although the role of ER signaling in maintaining function in these systems, as well as the changes in these systems associated with aging populations have been reported on Earth, a Medline search using the terms "spaceflight" and "estrogen receptors" shows no published research in this area. Thus, there are major knowledge gaps regarding whether changes in these systems during spaceflight may have a common mechanism due to alterations in ER as well as androgen receptor signaling in women and men. Importantly, the emphasis on ER signaling and relative lack of attention to androgens in both sexes could create false impressions that estrogen is more affected by aging and spaceflight than androgens and that women are more likely than men to have health problems in space, which is not supported by the literature. Because bone density is maintained by estrogen in both men and women, declining testosterone and the decrease in subsequent aromatization to estrogen would also impact bone health in men.

\section{Bone and cardiovascular health}

There are sex differences in response to stressors that affect the reproductive axis, and these can have long-term consequences for bone and cardiovascular health. Although contraceptive use is common among female astronauts, those that suppress ovarian function for extended periods [e.g., Depo-Provera or other contraceptives containing depot medroxyprogesterone acetate (DMPA), and Noristerat, Norigest, Doryxas, or others containing norethisterone enantate (NET-EN)] have been shown to adversely affect women's bone density on Earth. ${ }^{45,46}$ Thus, if used in space, certain OC formulations may compound bone loss resulting from microgravity in female astronauts. This raises the question of whether total estrogen exposure would be reduced for female astronauts using those contraceptives on long-duration missions that, in turn, could impact bone health, muscle strength, and cardiovascular risks. (This argument is predicated on the assumption that female astronauts continue to cycle during spaceflight.) Thus, in women, increased risk for cardiovascular disease may be both directly and indirectly related to disruption of ovarian function, perhaps through binding of the adrenal cortical hormones to progesterone receptors and membrane surface receptors that also bind estrogen. ${ }^{47,48}$

\section{Brain-behavior relationships}

Sleep. Flight-induced changes in gonadal hormone release may be the source of a nonreproductive functional outcome, namely altered sleep patterns. ${ }^{49}$ Sleep-wake cycles are also disrupted in Earth-based, long-duration microgravity simulations. ${ }^{50}$ Sleep quality is affected by some stressor exposures and is correlated with circulating testosterone and estradiol levels. ${ }^{51-55}$ Conversely, sleep deprivation disrupts normal gonadal hormone secretion ${ }^{56}$ and increases glucocorticoid release, ${ }^{57}$ thus potentially causing a positive feedback loop. Gonadal hormones affect the activities of brain monoamines, acetylcholine, and orexin, ${ }^{58-61}$ all neurotransmitters involved in maintaining wakeful state, sleep state, or transitions between sleep states. ${ }^{62}$

Reproduction and rearing. Despite the consideration that in the distant future, human reproduction is likely to occur in space, ${ }^{63}$ the current literature base is insufficient, limiting speculation about the possibility that intricate and complex phases of reproduction in mammals-including mating, fertilization, implantation, placentation, embryogenesis, organogenesis, prenatal and postnatal development, birth, lactation, and suckling - can occur in space.

In adult animals flown in space, fertilization difficulties could potentially occur due to disruption of hypothalamic neurochemistry important for proceptivity and receptivity components of copulation. Several hypothalamic transmitters are affected by physical factors involved during spaceflight. Oxytocin is both responsive to HPG axis functioning and attenuates HPA axis activation during stressor exposure in women. $^{26,27}$ Hypothalamic oxytocin is also critically involved in female sexual receptivity. ${ }^{64}$ Unlike many other hormones, hypothalamic oxytocin remains reduced at 18 weeks following spaceflight in rodents. ${ }^{14}$ This effect may be more significant in women, as OCs reduce circulating oxytocin levels. ${ }^{28}$ Given the influence of spaceflight and OC use on oxytocin release, further research is necessary to determine whether this combination could have long-term effects on reproductive health.

Enduring changes in oxytocin following spaceflight ${ }^{14}$ might be critical in postpartum behaviors, as oxytocin is implicated in social bonding. Thus, the implications of longduration spaceflight for the viability of the immediate offspring as well as the subsequent generation of offspring are an unknown, possibly ever-lasting effect within the families of those chosen to participate in such missions.

\section{Sex and Gender Considerations in Astronaut Reproductive Health}

Gender roles and responsibilities can impact health and health outcomes. Although reproduction is a biological process, societal roles for parents including that of women functioning as the primary caregiver often require women to take extended family medical leave and, for some, a hiatus from their career. While paternity leave is more common now than in past decades, the majority of U.S. fathers do not take more than one week of leave after the birth of a child. ${ }^{65}$ As compared with male astronauts, female astronauts delay reproduction (Table 1), which may be based, in part, on gender role requirements. Further, the biological processes that ensure successful reproduction are impacted by aging, a factor that can lead to infertility and pregnancy complications in those who delay childbearing. ${ }^{66}$ Thus, childbearing and childrearing events that occur along a continuum are examples where the variables of sex and gender collide.

Table 2 shows that in this astronaut cohort, the age of first mission and percent married is significantly different between men and women. Table 2 shows that male astronauts have a higher average number of children than female astronauts, and even with the low numbers of female astronauts, this finding was statistically significant. An important hypothesis to consider is that the gender component impacts this finding. 
Table 1. Reproductive Demographics of U.S. Astronauts

\begin{tabular}{lcc}
\hline & $\begin{array}{c}\text { Women }^{\mathrm{a}} \\
\mathrm{N}=47\end{array}$ & $\begin{array}{c}\text { Men }^{\mathrm{b}} \\
\mathrm{N}=192\end{array}$ \\
\hline $\begin{array}{c}\text { Number with at least } \\
\text { one child (\%) }\end{array}$ & $21(44.7 \%)$ & $161(83.9 \%)$ \\
$\begin{array}{c}\text { Average number of } \\
\text { children, amongst those } \\
\text { with at least one child } \\
\text { (range) }^{\mathrm{d}}\end{array}$ & $1.9(1-4)$ & $2.5(1-8)$ \\
$\begin{array}{c}\text { Average age at birth } \\
\text { of first child (range) }\end{array}$ & $34.8(25.7-46.5)$ & $29.2(17-52)$ \\
\hline
\end{tabular}

${ }^{a}$ Data extracted from National Aeronautics and Space Administration medical records, current as of 2014.

${ }^{\mathrm{b}}$ Data extracted from the Lifetime Surveillance of Astronaut Health Lifestyle Questionnaire, which was self-reported and collected at various points from February 22, 1995 through April 30, 2004.

${ }^{\mathrm{c}} p<0.0001$.

${ }^{\mathrm{d}} p=0.0349$.

e $p=0.0001 ; N=159$ due to missing data.

Because women are more likely to function as primary caregivers for their children and to take a hiatus from their career due to this parental role, we could speculate that some women choose to delay reproduction due to the extensive time required for preparation and training for space travel, which may be discordant with societal roles and responsibilities of parenting. This is an example of the complexity of the interplay of both sex and gender on reproductive health.

Review of the sex and gender interaction within each environmental stressor in space travel is beyond the scope of this particular work, but expanding gender impact beyond reproduction is worth exploring. Consider sleep deprivation, a well-known stressor in space travel, discussed above. Research on Earth indicates that sleep disruption impacts men and women differently and women experience sleep disruption at higher rates than men. ${ }^{69}$ Women subjectively report lower sleep quality as compared to men. ${ }^{70}$ In addition sleep disruption increases with aging and for women is most prominent in middle age through menopause. ${ }^{68}$ The median age

Table 2. General Demographics of U.S. ASTRONAUTS AS OF 2014

\begin{tabular}{|c|c|c|}
\hline & Women & Men \\
\hline Total number (\%) & $48(15.4 \%)$ & $282(84.6 \%)$ \\
\hline Selection years & 1978-2009 & 1959-2009 \\
\hline $\begin{array}{l}\text { Average age at } \\
\text { selection (range) }\end{array}$ & $32.8(26-47)$ & $34.8(25-45)$ \\
\hline $\begin{array}{l}\text { Number with at least } \\
\text { one spaceflight }(\%) \\
\text { [Mercury-3 }(1961) \\
\text { to Expedition-36 } \\
(2013) \text { ] }\end{array}$ & $43(89.6) \%$ & $260(92.2 \%)$ \\
\hline $\begin{array}{l}\text { Average age at first } \\
\text { transit (range) })^{\mathrm{a}}\end{array}$ & $38.3(32.1-55.7)$ & $41(32.2-58.8)$ \\
\hline $\begin{array}{l}\text { Number ever married } \\
\text { or divorced }(\%)^{\mathrm{b}}\end{array}$ & $39(81.3) \%$ & $275(97.5 \%)$ \\
\hline
\end{tabular}

for U.S. astronauts (first transit) is 38.3 years and for all transits, 40.9 years (versus 41 and 43.4 years, respectively, for men). Women have more difficulty resuming normal sleep patterns after sleep disruption. Terrestrial, sex-based research indicates that sleep disruption in women can increase levels of inflammatory markers including hs-CRP and coagulation factors such as von Willebrand factor that, in theory, would increase risk of cardiometabolic disease and cardiovascular events. $^{71}$

It is well known that women present more frequently with "atypical" symptoms of cardiovascular disease such as fatigue, heartburn, and dyspnea and are less likely to receive a workup for cardiovascular disease. In addition, women have sex-specific risk factors such as polycystic ovarian disease, gestational diabetes, and preeclampsia. ${ }^{67}$ Given that cardiovascular disease is the number one killer for men and women regardless of occupation, ${ }^{68}$ it will benefit both male and female astronauts for future NASA research platforms to include both variables: sex and gender.

Knowledge gaps in health differences of male and female space travelers remain due to lack of consideration and inclusion of gender and sex as unique variables in research platforms. Yet, biologically, cessation of reproductive capacity is more readily identifiable in women and a direct function of aging, again highlighting delayed reproduction, potential acceleration of aging, and the impact of gonadal radiation exposure related to space travel. Gender and sex have significant interplay, carrying highly distinctive roles for men and women within the health care system.

\section{Infrastructure}

There is a major need to improve the research and healthcare reporting infrastructure for the NASA Human Research Program. Low numbers of study participants, variable astronaut age, and OC usage all limit statistical robustness required to determine if there are significant effects of spaceflight on reproductive health. There is a crucial need for a coordinated effort to augment the infrastructure for basic research studies, with priorities established to include male and female subjects, human and animal, for the purpose of advancing understanding of sex and gender factors in relation to spaceflight.

\section{Research Recommendations}

Understanding of reproductive changes in men and women (pre-, during, and post-flight) that extend into the health and rearing of their offspring is limited. There is a critical lack of information about the effects of spaceflight on gonadal function and bone loss, as well as about effects of cosmic radiation on women's health. Basic information is needed regarding effects of microgravity and circadian disruption on gonadotropin release and on concentrations of sex hormones in both women and men. Examination of the effects of OC usage on HPA axis tone pre-, during, and post-flight is warranted. Basic studies of the causes of the prolonged oxytocin reduction, the functional significance of such reductions, and whether flight duration has a role in the magnitude or duration of the reduction are needed. Development and use of mammalian models to ascertain the detrimental effects of spaceflight stressors on male and female physiology and behavior on prolonged flights, and effects on offspring are warranted. 
Active prevention of urinary tract stones and voiding difficulties will be essential for extended missions. Studies of urinary tract manipulation in a low-gravity environment are needed. Better understanding of the risk factors for urinary tract infection in space is warranted, including changes in the urinary microbiome and bacterial behavior in space as well as stability of antibiotic formulations throughout long mission durations. Gonadal hormones are not sex-specific. Astronaut and post-flight studies need to be expanded to examine estrogen signaling, including regulation of ER in men and testosterone in women, particularly in relation to bone and cardiovascular function. Potential options for assisted reproductive technologies for male and female astronauts should be considered, e.g., sperm and oocyte cryopreservation and informed consent.

\section{Acknowledgments}

Jessica Garcia and Mary Wear, Johnson Space Center, provided key epidemiological data for this report from the Lifetime Surveillance of Astronaut Health (LSAH). David Dinges, Namni Goel, Janice Huff, Richard Jennings, and Virginia Wotring provided critical comments on an earlier draft of this manuscript.

\section{Author Disclosure Statement}

No competing financial interests exist.

\section{References}

1. Hay M., Mark S Seigel B. Sex, space and environmental adaptation: A National workshop on research priorities on sex differences in adaptation to challenging environments. National Aeronautics and Space Administration and $\mathrm{Na}-$ tional Center for Gender Physiology and Environmental Adaptation, University of Missouri, Columbia, Missouri, November 12-14, 2002.

2. Cucinotta F.A., Kim M.Y., Willingham V., George K.A. Physical and biological organ dosimetry analysis for International Space Station astronauts. Radiat Res 2008;170:127-138,

3. Rubin P. Law and order of radiation sensitivity: Absolute versus relative. In: Vaeth JM, Meyer JL, eds. Frontiers of radiation therapy and oncology. Basel: Karger, 1989:7-40.

4. International Commission on Radiological Protection (ICRP). Publication 41. Non-Stochastic effects of ionizing radiation. Oxford: Pergamon Press, 1984:1-33.

5. National Academy of Sciences/National Research Council (NAS/NRC). Health effects of exposure to low levels of ionizing radiation: BEIR V. Washington, DC: National Academy Press, 1990:1-436.

6. Straume T, Blattnig S, Zietlin C. Radiation hazards and the colonization of Mars: Brain, body, pregnancy, in-utero development, cardio, cancer, degeneration. J Cosmol 2010;12: 3992-4033.

7. National Council on Radiation Protection and Measurements (NCRP). Report 132. Radiation Protection Guidance for Activities in Low Earth Orbit. Bethesda, MD: NCRP, 2000:1-186.

8. NCRP. Report 98. Guidance on Radiation Received in Space Activities. Bethesda, MD: NCRP, 1998.

9. Cucinotta FA, Kim MY, Chappell L. Space radiation cancer risk projections and uncertainties- 2012. NASA TP 2013-217375, 2013.
10. Nichiporuk IA, Evdokimov VV, Erasova VI, Smirnov OA, Goncharova AG, Vassilieva Yu G, Vorobiev DV. Male reproductive system in conditions of bed-rest in a headdown tilt. J Gravit Physiol 1998;5:P101-102.

11. Tash JS, Johnson DC, Enders GC. Long-term (6-week) hindlimb suspension inhibits spermatogenesis in adult male rats. J Appl Physiol 2002;92:1191-1198.

12. Tash JS, Roby KF, Gupta V, Holets L. Long term spaceflight impacts on male reproductive health. In: Fundamental Space Biology Division, ed. NASAPRS Task book. NASA, 2012. https://taskbook.nasa-prs.com Publication Task Books. Rel. 6/29/2012.

13. Garovic V, Bailey K, Boerwinkle E, Hunt S, Weder A, Curb J, Mosley TH Jr., Wiste HJ, Turner ST. Hypertension in pregnancy as a risk factor for cardiovascular disease later in life. J Hypertens 2010;28:826-833.

14. Uno A, Takeda N, Horii A, Morita M, Yamamoto Y, Yamatodani A, Kubo T. Histamine release from the hypothalamus induced by gravity change in rats and space motion sickness. Physiol Behav 1997;61:883-887.

15. Blanc S, Somody L, Gharib A, Gauquelin G, Gharib C, Sarda N. Counteraction of spaceflight-induced changes in the rat central serotonergic system by adrenalectomy and corticosteroid replacement. Neurochem Int 1998;33:375382.

16. Garcia-Ovejero D, Trejo JL, Ciriza I, Walton KD, García-Segura LM. Space flight affects magnocellular supraoptic neurons of young prepuberal rats: transient and permanent effects. Brain Res Dev Brain Res 2001; 130:191-205.

17. Kastello GM, Sothmann MS. Brain norepinephrine changes with simulated weightlessness and relation to exercise training. Physiol Behav 1999;66:885-891.

18. Morita H, Abe C, Awazu C, Tanaka K. Long-term hypergravity induces plastic alterations in vestibulo-cardiovascular reflex in conscious rats. Neurosci Lett 2007;412:201205.

19. Strollo F, Riondino G, Harris B, et al. The effect of microgravity on testicular androgen secretion. Aviat Space Environ Med 1998;69:133-136.

20. Ortiz RM, Wade CE, Morey-Holton E. Urinary excretion of $\mathrm{LH}$ and testosterone from male rats during exposure to increased gravity: Post-spaceflight and centrifugation. Proc Soc Exp Biol Med. 2000;225:98-102.

21. Liang X, Zhang L, Wan Y, et al. Changes in the diurnal rhythms during a 45-day head-down bed rest. PloS One 2012;7:e47984.

22. Smith SM, Heer M, Wang Z, Huntoon CL, Zwart SR. Long-duration space flight and bed rest effects on testosterone and other steroids. J Clin Endocrinol Metab 2012; 97:270-278.

23. Crucian B, Lee $P$, Stowe R, et al. Immune system changes during simulated planetary exploration on Devon Island, high arctic. BMC Immunol 2007;8:7.

24. Dijk DJ, Neri DF, Wyatt JK, et al. Sleep, performance, circadian rhythms, and light-dark cycles during two space shuttle flights. Am J Physiol Regul Integr Comp Physiol 2001;281:R1647-1664.

25. Rai B, Kaur J. Salivary stress markers and psychological stress in simulated microgravity: 21 days in 6 degrees headdown tilt. J Oral Sci 2011;53:103-107.

26. Stowe RP, Sams CF, Pierson DL. Effects of mission duration on neuroimmune responses in astronauts. Aviat Space Environ Med 2003;74:1281-1284. 
27. Mehta SK, Kaur I, Grimm EA, Smid C, Feeback DL, Pierson DL. Decreased non-MHC-restricted (CD56+) killer cell cytotoxicity after spaceflight. J Appl Physiol 2001;91:1814-1818.

28. Suh BY, Liu JH, Rasmussen DD, Gibbs DM, Steinberg J, Yen SS. Role of oxytocin in the modulation of ACTH release in women. Neuroendocrinology 1986;44:309-313.

29. Heinrichs M, Baumgartner T, Kirschbaum C, Ehlert U. Social support and oxytocin interact to suppress cortisol and subjective responses to psychosocial stress. Biol Psychiatry 2003;54:1389-1398.

30. Salonia A, Nappi RE, Pontillo M, et al. Menstrual cyclerelated changes in plasma oxytocin are relevant to normal sexual function in healthy women. Horm Behav 2005;47: 164-169.

31. Rohleder N, Wolf JM, Piel M, Kirschbaum C. Impact of oral contraceptive use on glucocorticoid sensitivity of proinflammatory cytokine production after psychosocial stress. Psychoneuroendocrinology 2003;28:261-273.

32. Sulak P, Lippman J, Siu C, Massaro J, Godwin A. Clinical comparison of triphasic norgestimate/35 micrograms ethinyl estradiol and monophasic norethindrone acetate/20 micrograms ethinyl estradiol. Cycle control, lipid effects, and user satisfaction. Contraception 1999;59:161-166.

33. Wiegratz I, Kutschera E, Lee JH, et al. Effect of four oral contraceptives on thyroid hormones, adrenal and blood pressure parameters. Contraception 2003;67:361-366.

34. Newkirk D. Almanac of Soviet manned space flight. Houston, TX: Gulf Publishing Company, 1990:278-281.

35. Jones JA et al. Genitourinary issues during spaceflight: A review. J Impot Res 2005;17:S64-S67.

36. Dall'Era J, Kim F, Chandhoke S. Gender differences among Hispanics and Caucasians in symptomatic presentation of kidney and ureteral stones. J Endourol 2005; 19:283.

37. Magliano E et al. Gender and age-dependent etiology of community-acquired urinary tract infections. ScientificWorld Journal 2012;2012:349597.

38. Wolfe A, Toh E, Shibata N, et al. Evidence of uncultivated bacteria in the adult female bladder. J Clin Microbiol 2012;50:1376.

39. Lamonerie L, Marret E, Deleuze A, Lembert N, Dupont M, Bonnet F, et al. Prevalence of postoperative bladder distention and urinary retention detected by ultrasound measurement. Br J Anesthesia 2004;92:544.

40. Keita H, Diouf E, Tubach F, et al. Predictive factors of early postoperative urinary retention in the postanesthesia care unit. Anesth Analg 2005;101:592.

41. National Aeronautics and Space Administration, NASA Human Research Wiki: Evidence Report. Available at https:// humanresearchwiki.jsc.nasa.gov/images/e/ec/EvidenceReport .pdf $\backslash$ Accessed April 1, 2014.

42. Griebling TL. Urinary Tract Infection in Women. In: Litwin MS, Saigal CS, ed. Urologic diseases in America. U.S. Department of Health and Human Services, Public Health Service, National Institutes of Health, National Institute of Diabetes and Digestive and Kidney Diseases. Washington, DC: U.S. Government Printing Office, 2007: 588-619.

43. National Aeronautics and Space Administration, NASA Human Research Wiki: Urinary Tract Infection. Available at https://humanresearchwiki.jsc.nasa.gov/index.php? title=Urinary_Tract_Infectionhttps://humanresearchwiki.jsc .nasa.gov/index.php?title=Urinary_Tract_Infection Accessed April 1, 2014.
44. Vernikos J, Scneider VS. Space, gravity and the physiology of aging: Parallel or convergent disciplines? A mini-review. Gerontology 2010:56:157-166.

45. Nappi C, Bifulco G, Tommaselli GA, Gargano V, Di Carlo C. Hormonal contraception and bone metabolism: A systematic review. Contraception 2012;86:606-621.

46. Lanza LL, McQuay LJ, Rothman KJ, et al. Use of depot medroxyprogesterone acetate contraception and incidence of bone fracture. Obstet Gynecol 2013;121:593-600.

47. Feldman RD, Gros R. Rapid vascular effects of steroids: A question of balance? Can J Cardiol 2010;26:22A-226A.

48. Gros R, Ding Q, Sklar LA, et al. GPR30 expression is required for the mineralocorticoid receptor-independent rapid vascular effects of aldosterone. Hypertension 2011;57:442-451.

49. Andersen ML, Guindalini C, Santos-Silva R, Bittencourt LR, Tufik S. Androgen receptor CAG repeat polymorphism is not associated with erectile dysfunction complaints, gonadal steroids, and sleep parameters: Data from a population-based survey. J Androl 2011;32:524-529.

50. Caufriez A, Leproult R, L'Hermite-Baleriaux M, Kerkhofs M, Copinschi G. Effects of a 3-week dehydroepiandrosterone administration on sleep, sex steroids and multiple 24-h hormonal profiles in postmenopausal women: a pilot study. Clin Endocrinol (Oxf) 2013;79:716-724.

51. Hollander LE, Freeman EW, Sammel MD, Berlin JA, Grisso JA, Battistini M. Sleep quality, estradiol levels, and behavioral factors in late reproductive age women. Obstetr Gynecol 2001;98:391-397.

52. Opstad PK, Aakvaag A. Decreased serum levels of oestradiol, testosterone and prolactin during prolonged physical strain and sleep deprivation, and the influence of a high calorie diet. Eur J Appl Physiol Occup Physiol 1982;49:343-348.

53. Paul KN, Laposky AD, Turek FW. Reproductive hormone replacement alters sleep in mice. Neurosci Lett 2009;463: 239-243.

54. Sowers MF, Zheng H, Kravitz HM, et al. Sex steroid hormone profiles are related to sleep measures from polysomnography and the Pittsburgh Sleep Quality Index. Sleep 2008;31:1339-1349.

55. Yamaoka S. Modification of circadian sleep rhythms by gonadal steroids and the neural mechanisms involved. Brain Res 1980;185:385-398.

56. Wu JL, Wu RS, Yang JG, et al. Effects of sleep deprivation on serum testosterone concentrations in the rat. Neurosci Lett 2011;494:124-129.

57. Suchecki D, Lobo LL, Hipolide DC, Tufik S. Increased ACTH and corticosterone secretion induced by different methods of paradoxical sleep deprivation. J Sleep Res 1998;7:276-281.

58. Biegon A, McEwen BS. Modulation by estradiol of serotonin receptors in brain. J Neurosci 1982;2:199-205.

59. Lapchak PA, Araujo DM, Quirion R, Beaudet A. Chronic estradiol treatment alters central cholinergic function in the female rat: Effect on choline acetyltransferase activity, acetylcholine content, and nicotinic autoreceptor function. Brain Res 1990;525:249-255.

60. Martinez-Conde E, Leret ML, Diaz S. The influence of testosterone in the brain of the male rat on levels of serotonin (5-HT) and hydroxyindole-acetic acid (5-HIAA). Comp Biochem Physiol C. 1985;80:411-414.

61. Russell SH, Small CJ, Kennedy AR, et al. Orexin A interactions in the hypothalamo-pituitary gonadal axis. Endocrinology 2001;142:5294-5302.

62. Siegel JM. The neurotransmitters of sleep. J Clin Psychiatry 2004;65 Suppl 16:4-7. 
63. Murad A. Contraception in the cosmos: the combined oral contraceptive pill in space. J Fam Plann Reprod Health Care 2008;34:55-59.

64. Benelli A, Poggioli R, Luppi P, Ruini L, Bertolini A, Arletti R. Oxytocin enhances, and oxytocin antagonism decreases, sexual receptivity in intact female rats. Neuropeptides 1994;28: 288-302.

65. Hara Y, Hegewisch A. Maternity, paternity, and adoption leave in the United States. Institute for Women's Policy Research, May 2013. Available at: www.iwpr.org/ publications/pubs Accessed April 1, 2014.

66. Beemsterboer SN, Homburg R, Gorter NA, Schats R, Hompes PG, Lambalk CB. The paradox of declining fertility but increasing twinning rates with advancing maternal age. Hum Reprod 2006;21:1531-1532.

67. Schenck-Gustavson, K., Rees, M. Cardiology for gynecologists: A minireview. Maturitas 2013;75:386-391.

68. National Center for Health Statistics, Centers for Disease Control and Prevention. Fast Stats: Heart Disease. Avail- able at: www.cdc.gov/nchs/fastats/heart.htm Accessed October 29, 2014.

69. Rye DB. Restless legs syndrome and periodic leg movements of sleep. Neurol Clin. 2012;30:1137-1166.

70. Ohayon MM. Difficulty in resuming or inability to resume sleep and the links to daytime impairment: Definition, prevalence and comorbidity. J Psychiatr Res 2009;43:934-940.

71. Knutson KL. Sociodemographic and cultural determinants of sleep deficiency: Implications for cardiometabolic disease risk. Soc Sci Med 2013;79:7-15.

Address correspondence to: April E. Ronca, PhD Space Biosciences Research Branch NASA Ames Research Center MS 236-7

Mountain View, CA 94035

E-mail: aronca@wakehealth.edu 